This item was submitted to Loughborough's Research Repository by the author.

Items in Figshare are protected by copyright, with all rights reserved, unless otherwise indicated.

\title{
Atomic structure of biodegradable Mg-based bulk metallic glass
}

\section{PLEASE CITE THE PUBLISHED VERSION}

http://dx.doi.org/10.1039/c4cp03714f

\section{PUBLISHER}

Royal Society of Chemistry / @ Owner Societies

\section{VERSION}

AM (Accepted Manuscript)

\section{PUBLISHER STATEMENT}

This work is made available according to the conditions of the Creative Commons Attribution-NonCommercialNoDerivatives 4.0 International (CC BY-NC-ND 4.0) licence. Full details of this licence are available at: https://creativecommons.org/licenses/by-nc-nd/4.0/

\section{LICENCE}

CC BY-NC-ND 4.0

\section{REPOSITORY RECORD}

Christie, Jamieson. 2015. “Atomic Structure of Biodegradable Mg-based Bulk Metallic Glass". Loughborough University. https://hdl.handle.net/2134/18285. 


\title{
Atomic structure of biodegradable Mg-based bulk metallic glass
}

\author{
J. K. Christie \\ Department of Chemistry, University College London, \\ 20 Gordon Street, London, WC1H 0AJ, UK and \\ Department of Materials, Loughborough University, Loughborough, LE11 3TU, UK
}

\begin{abstract}
We have used highly accurate first-principles molecular dynamics simulations to elucidate the structure of $\mathrm{Mg}_{60} \mathrm{Zn}_{35} \mathrm{Ca}_{5}$ and $\mathrm{Mg}_{72} \mathrm{Zn}_{23} \mathrm{Ca}_{5}$ bulk metallic glasses, which are candidate materials for biomedical implants; these two compositions exhibit different behaviours when implanted. The environments of each species are different, and average coordination numbers are $\sim 13$ for $\mathrm{Mg}$, $\sim 11$ for Zn and $\sim 18-19$ for Ca. A wide range of local environments were found and icosahedral motifs, often seen in bulk metallic glasses, were among the most common for both Mg and Zn. Through the computation of a chemical short-range order parameter, a moderate avoidance of Zn$\mathrm{Zn}$ bonding over $\mathrm{Zn}-\mathrm{Mg}$ or $\mathrm{Zn}-\mathrm{Ca}$ was observed. No statistically significant difference in structure was observed between the two compositions.
\end{abstract}




\section{INTRODUCTION}

Bulk metallic glasses (BMGs) have a unique range of properties that make them of considerable scientific and technological interest [1-5]. Their atomic structures are amorphous, without crystalline order, which means that no dislocation defects exist, and so BMGs can have strengths "far exceeding any conventional metallic material" [6]. Their amorphous structure means that they are not limited to specific stoichiometries, and so the range of possible glass compositions is larger than that for crystalline alloys. In this work, we investigate the structure of BMGs containing magnesium, zinc and calcium, which in the Cheng and Ma classification of AM (alkali and alkaline earth) + LTM (late transition metal), "have not been systematically studied" [7].

Mg-Zn-Ca glasses are strong candidates for use as medical implants. Magnesium, zinc and calcium are all elements found within the human body, and the biocompatibility of these glasses has been shown both in vitro [8] and in vivo [9]. Glasses in the Mg-Zn-Ca system have very low densities, comparable to human bone, compared to other BMGs. Mg-based metallic glasses have excellent glass-forming ability (GFA) and also often have elastic moduli comparable to that of human bone [10], which minimises stress mismatch for orthopaedic applications.

Crystalline $\mathrm{Mg}$ alloys evolve hydrogen when implanted into the body, which is detrimental to patient health, but recent work [11] shows that compositions of Mg-Zn-Ca glasses with $>28 \%$ Zn form a Zn-rich passivating surface layer which inhibits the release of hydrogen. The development of a BMG which does not evolve hydrogen means that "metallic glasses hold much promise for improving next-generation biodegradable implants" [12].

Therefore, in order to optimise these glasses for implantation, or for any other application, it is necessary to understand the connections between the glass composition, its atomic structure and relevant macroscopic properties such as the formation of a surface layer, or

glass degradation rate, which is also known to depend on composition [13]. We use very accurate first-principles computer simulations to investigate the atomic structure of two compositions of $\mathrm{Mg}$-Zn-Ca glass, one of which $\left(\mathrm{Mg}_{60} \mathrm{Zn}_{35} \mathrm{Ca}_{5}\right)$ forms the passivating surface layer, and one of which $\left(\mathrm{Mg}_{72} \mathrm{Zn}_{23} \mathrm{Ca}_{5}\right)$ does not. Computer simulation has proved invaluable in complementing experimental investigations into glass structure, including in elucidating the structure of glasses used for implantation into the body [14-18]. 
Despite this interesting application, the structure of $\mathrm{Mg}-\mathrm{Zn}-\mathrm{Ca}$ glasses is not yet fully understood. Initial studies were focussed on $\mathrm{Mg}$-Zn binary glasses, in which empirical interatomic force fields have been used to show that icosahedral structural motifs are the dominant local configuration in the binary glass $\mathrm{Mg}_{70} \mathrm{Zn}_{30}$ [19-21], and icosahedra have also been shown by first-principles $\mathrm{MD}$ to dominate in $\mathrm{Mg}_{90} \mathrm{Ca}_{10}$ glass [22], where some were also seen to arrange in an ordered way leading to a quasicrystalline phase. The presence of icosahedra is also seen in metallic glasses more generally [23-25], and their presence is often linked to increased GFA.

Neutron and x-ray diffraction on the binary glass $\mathrm{Mg}_{72} \mathrm{Zn}_{28}$ shows a slight preference for homopolar Zn-Zn bonding compared to similar binary crystalline compounds [26]. Experimental investigation of the structure of the ternary glasses has been limited to the Ca-rich part of the Mg-Zn-Ca system, where neutron and x-ray diffraction have been combined with first-principles simulation [27], to show efficient structural packing of solute-centred clusters, with an increasing amount of icosahedra with increasing $\mathrm{Mg}$ content, up to 25 at. \%.

More recent computational work has considered ternary Mg-Zn-Ca compositions. The first computational study of biomedically relevant compositions in this system used an empirical tight-binding interatomic potential to investigate the glass microstructure [28]. The use of an empirical potential relies on an approximate description of the interatomic forces, and this can lead to errors, particularly when modelling the creation and breaking of chemical bonds. By contrast, first-principles molecular dynamics (MD) employs a quantum-mechanical description of the electronic properties, deriving the forces without $a$ priori assumptions about the atomic interactions. First-principles MD has been used to investigate the structure [29] and elastic properties [10] of biomedically relevant $\mathrm{Mg}-\mathrm{Zn}-\mathrm{Ca}$ compositions. Li et al. [29] have proposed that as the Zn content of the glass increases, a percolated Zn-Zn network forms and extends throughout the whole glass, with implications for corrosion resistance.

In this work, we also use very accurate first-principles MD simulations to characterise the structure of two biomedically relevant glass compositions, which were not previously simulated. We characterise the structure and bonding, including commenting on any preferential bonding, and search for structural features which could explain the composition dependence of the formation of the surface layer which makes these glasses suitable as biomedical implants. 


\section{METHODS}

Born-Oppenheimer molecular dynamics simulations were performed by the mixed planewave/Gaussian-basis-set CP2K code [30], using the generalised gradient approximation to density-functional theory with PBE exchange-correlation functionals [31]. All atomic species were represented using a double-zeta valence polarised (DZVP) basis set [32]. The planewave energy cutoff was $600 \mathrm{Ry}$, and the MD timestep was 1.0 fs. Periodic boundary conditions were used throughout.

Two biomedically relevant [11] compositions were modelled: $\mathrm{Mg}_{60} \mathrm{Zn}_{35} \mathrm{Ca}_{5}$ and $\mathrm{Mg}_{72} \mathrm{Zn}_{23} \mathrm{Ca}_{5}$. The density of $\mathrm{Mg}_{72} \mathrm{Zn}_{23} \mathrm{Ca}_{5}$ is known experimentally [33] to be $2.84 \mathrm{~g} \mathrm{~cm}^{-3}$ and that for $\mathrm{Mg}_{60} \mathrm{Zn}_{35} \mathrm{Ca}_{5}$, which was not available experimentally or via glass property databases, was estimated at $3.246 \mathrm{~g} \mathrm{~cm}^{-3}$. In this work, one model of each composition was prepared. For each model, a cubic periodic box was chosen to give this density and the starting configurations were selected by randomly and independently placing 120 atoms of the appropriate compositions into the box, such that no two atoms were closer than $\sim 85-90$ $\%$ of their expected interatomic separation. Initial velocities were set to zero.

Simulated glass models are typically prepared using the melt-and-quench method: after atoms are quasi-randomly inserted into the simulation box as above, the model is then equilibrated in the liquid state, well above the melting temperature of the glass. The model is then cooled, usually by reducing the temperature in steps, before the production run is performed at room temperature. First-principles molecular dynamics and the melt-andquench method have been used to prepare glass models whose structural properties are in agreement with experiment for silicate [34, 35], phosphate [36-38] and metallic [22, 39-41] glasses.

For each model, as prepared above, a molecular dynamics trajectory was started in the NVT ensemble at $1500 \mathrm{~K}$ until the model was well equilibrated, which was assessed by examining the actual and mean-square atomic displacements, and took $\sim 15$ ps of simulation time. Each model was then cooled for $7-10$ ps at each of $1100 \mathrm{~K}$ and $700 \mathrm{~K}$, before being run for 5 ps at $300 \mathrm{~K}$. The last two-thirds of the $300 \mathrm{~K}$ run form the production run, and unless otherwise stated, all data given this paper are averaged over that part. The cooling rate of these glasses is $65-80 \mathrm{~K} / \mathrm{ps}$, which is faster than that used for the experimental preparation of metallic glasses, however, cooling rates of this order of magnitude are widely 


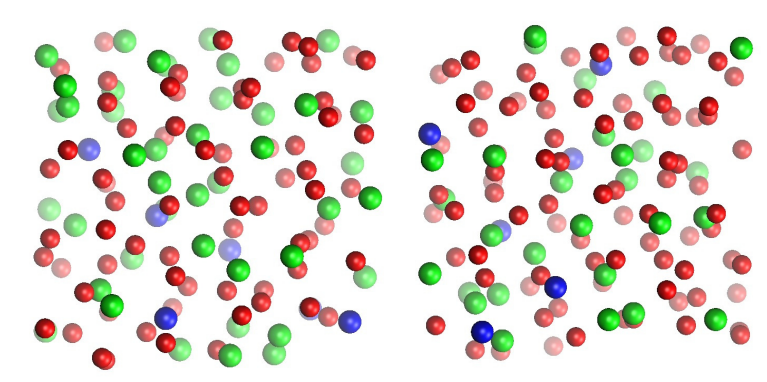

FIG. 1: Views of the $\mathrm{Mg}_{60} \mathrm{Zn}_{35} \mathrm{Ca}_{5}$ (left) and $\mathrm{Mg}_{72} \mathrm{Zn}_{23} \mathrm{Ca}_{5}$ (right) compositions. The colours are: magnesium (red), zinc (green), calcium (blue).

used, as in the works above.

\section{RESULTS}

Pictures of the models are shown in Figure 1.

The partial pair-correlation function $g_{\alpha \beta}(r)$ is frequently used to describe the atomic structure of disordered materials and is defined by

$$
g_{\alpha \beta}(r)=\frac{1}{N c_{\alpha} c_{\beta} \rho} \sum_{i=1}^{N_{\alpha}} \sum_{j=1}^{N_{\beta}} \delta\left(r-r_{i j}\right),
$$

where $N_{\alpha}$ is the number of atoms of species $\alpha, N$ is the total number of atoms, $c_{\alpha}=N_{\alpha} / N$ is the number concentration of species $\alpha, \rho$ is the bulk (number) density, and $r_{i j}$ is the interatomic separation of atoms $i$ and $j$. We computed the partial pair-correlation functions for our models, which are shown in Figure 2.

In Table I, we compare our simulated bond lengths, defined as the first peak in the relevant partial pair-correlation function (Figure 2), to bond lengths obtained from simulation and experiment on related metallic glass systems, as well as to their metallic and covalent bond lengths, and bond lengths found from various crystalline compounds. It is clear that our distances are in good agreement with those found in other studies [10, 22, 27, 29, 42], which validates our simulation methodology and ensures that we can be confident in our conclusions.

Interestingly, the bond lengths for the binary glasses, both from experiment and simulation, are often longer than for the ternary glasses, implying significant structural changes 


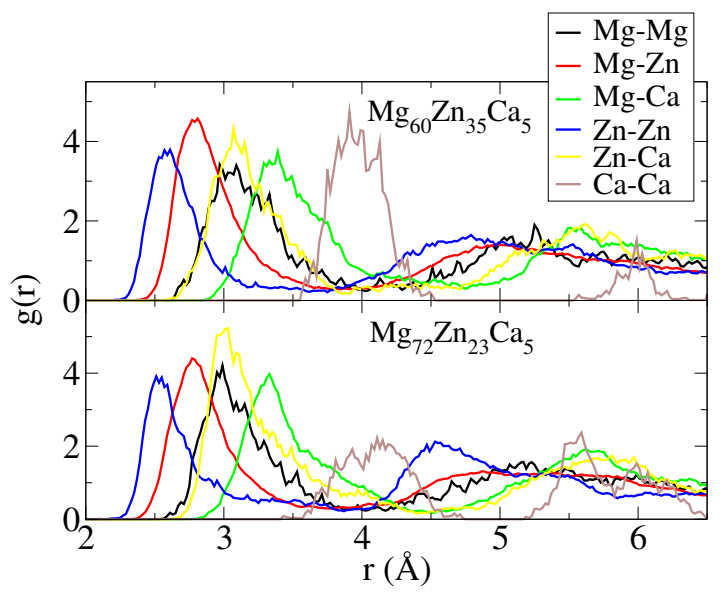

FIG. 2: Partial pair-correlation functions $g(r)$.

on the incorporation of calcium. Calcium is the largest of these three atoms, and we will see (Table II below) that it has the largest coordination number. Its first neighbour shell is likely to be larger than that for the other atoms and we can speculate that the incorporation of $\mathrm{Ca}$ into the glass reduces space available, constraining other bond lengths to be smaller.

The pair-correlation functions (Figure 2) and bond lengths (Table I) do not change significantly with composition. The small number of atoms in our models leads to a moderate amount of noise on the $g(r)$ curves, and any associated small differences are mainly due to this statistical noise. This is particularly prevalent with partial $g(r)$ 's involving calcium, the least prevalent atom, and very little quantitative information can be inferred from the Ca-Ca $g(r)$, which, indeed, is sometimes not given to avoid drawing unfounded conclusions $[29]$.

The total coordination number distribution (Figure 3) is wide for each species and remains almost constant with composition: Mg has $\sim 13$ nearest neighbours, $\mathrm{Zn}$ has $\sim 11$ and $\mathrm{Ca}$ has $\sim 18-19$. To investigate the partial coordination numbers (Table II) and any changes with composition, we have given the ratio of each partial coordination number between the two compositions and compared it to that expected if the atoms in the first coordination shell were distributed in proportion to their prevalence, in Table III. We have also computed the chemical short-range order (CSRO) parameter $\eta_{\alpha \beta}$, which is defined as

$$
\eta_{\alpha \beta}=1-\mathrm{CN}_{\alpha \beta} /\left(c_{\beta} \mathrm{CN}_{\alpha}\right)
$$

where $\mathrm{CN}_{\alpha \beta}$ is the partial coordination number of species $\beta$ with respect to species $\alpha, c_{\alpha}$ is 


\begin{tabular}{|c|c|c|c|c|c|c|}
\hline & \multicolumn{6}{|c|}{ Bond length $(\AA)$} \\
\hline & $\mathrm{Mg}-\mathrm{Mg}$ & $\mathrm{Mg}-\mathrm{Zn}$ & $\mathrm{Mg}-\mathrm{Ca}$ & $\mathrm{Zn}-\mathrm{Zn}$ & $\mathrm{Zn}-\mathrm{Ca}$ & $\mathrm{Ca}-\mathrm{Ca}$ \\
\hline $\mathrm{Mg}_{60} \mathrm{Zn}_{35} \mathrm{Ca}_{5}$ & 3.05 & 2.80 & 3.40 & 2.60 & 3.05 & 3.95 \\
\hline $\mathrm{Mg}_{72} \mathrm{Zn}_{23} \mathrm{Ca}_{5}$ & 3.00 & 2.75 & 3.35 & 2.55 & 3.05 & 4.10 \\
\hline $\mathrm{Mg}_{75-x} \mathrm{Zn}_{20+x} \mathrm{Ca}_{5}$ ([29], simul.) & 3.14 & 2.85 & 3.47 & 2.62 & 3.18 & not stated \\
\hline $\mathrm{Mg}_{62-72} \mathrm{Zn}_{24-32} \mathrm{Ca}_{4-6}([10]$, simul. $)$ & 3.10 & 2.92 & 3.57 & 2.69 & 3.25 & 4.15 \\
\hline $\mathrm{Ca}_{60} \mathrm{Mg}_{x} \mathrm{Zn}_{40-x}$ ([27], exp.) & 3.05 & 2.87 & 3.48 & 2.60 & 3.18 & 3.82 \\
\hline $\mathrm{Ca}_{40+x} \mathrm{Mg}_{25} \mathrm{Cu}_{35-x}$ ([42], exp.) & 3.12 & - & 3.45 & - & - & 3.76 \\
\hline $\mathrm{Mg}_{72} \mathrm{Zn}_{28}([26]$, exp. $)$ & 3.22 & 2.98 & - & 2.79 & - & - \\
\hline $\mathrm{Mg}_{90} \mathrm{Ca}_{10}([22]$, simul. $)$ & 3.18 & - & 3.67 & - & - & 4.05 \\
\hline metallic $[27]$ & 3.20 & 2.94 & 3.57 & 2.68 & 3.31 & 3.94 \\
\hline covalent $[27]$ & 2.82 & 2.63 & 3.17 & 2.44 & 2.98 & 3.52 \\
\hline crystalline [27] & $3.05-3.18$ & 3.04 & 3.62 & $2.53-4.15$ & $3.14-4.17$ & $3.61-4.32$ \\
\hline
\end{tabular}

TABLE I: Bond lengths in our compositions, compared to those measured experimentally and in simulation for related metallic glasses, as well as the metallic and covalent bond lengths, and the ranges of bond lengths found in relevant crystalline compounds. Bond lengths from this work are measured to the nearest $0.05 \AA$. Where several compositions are given in a row, the bond lengths are averaged over those compositions.

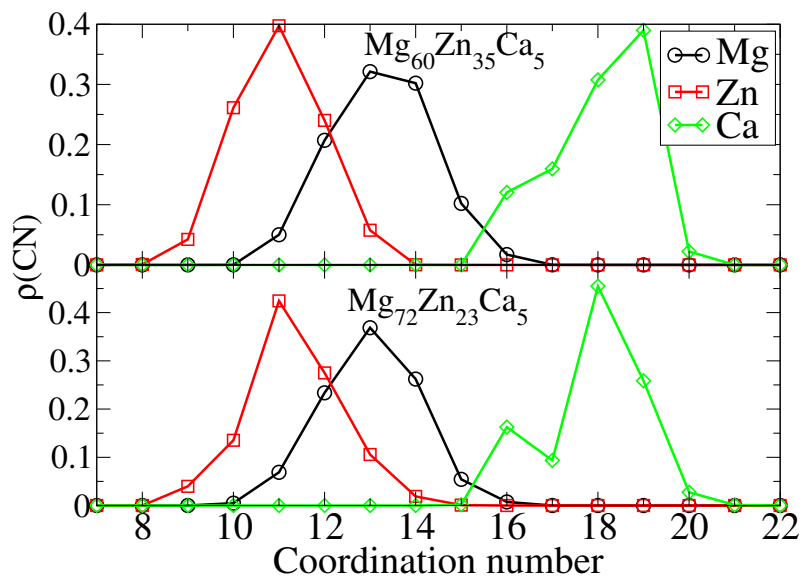

FIG. 3: Total coordination-number $(\mathrm{CN})$ distributions $\rho(\mathrm{CN})$. 


\begin{tabular}{|c|c|c|c|}
\hline pair & cutoff & $\begin{array}{r}\text { Coordinat } \\
\mathrm{Mg}_{60} \mathrm{Zn}_{35} \mathrm{Ca}_{5}\end{array}$ & $\begin{array}{l}\text { ion number } \\
\mathrm{Mg}_{72} \mathrm{Zn}_{23} \mathrm{Ca}_{5}\end{array}$ \\
\hline $\mathrm{Mg}-\mathrm{Mg}$ & $4.0 \AA$ & 8.0 & 9.5 \\
\hline $\mathrm{Mg}-\mathrm{Zn}$ & $3.75 \AA$ & 4.4 & 2.7 \\
\hline $\mathrm{Mg}-\mathrm{Ca}$ & $4.5 \AA$ & 0.9 & 0.9 \\
\hline $\mathrm{Zn}-\mathrm{Mg}$ & $3.75 \AA$ & 7.5 & 8.3 \\
\hline $\mathrm{Zn}-\mathrm{Zn}$ & $3.75 \AA$ & 2.9 & 2.0 \\
\hline $\mathrm{Zn}-\mathrm{Ca}$ & $4.5 \AA$ & 0.8 & 1.0 \\
\hline $\mathrm{Ca}-\mathrm{Mg}$ & $4.5 \AA$ & 11.3 & 12.7 \\
\hline $\mathrm{Ca}-\mathrm{Zn}$ & $4.5 \AA$ & 5.8 & 4.6 \\
\hline $\mathrm{Ca}-\mathrm{Ca}$ & $5.0 \AA$ & 1.0 & 0.7 \\
\hline
\end{tabular}

TABLE II: Average partial coordination numbers in our compositions (measured to the nearest $0.1)$.

\begin{tabular}{|c|cc|cc|}
\hline pair & $\mathrm{CN}_{r} \mathrm{CN}_{\mathrm{hom}}$ & $\eta_{\alpha \beta}\left(\mathrm{Mg}_{60} \mathrm{Zn}_{35} \mathrm{Ca}_{5}\right) \eta_{\alpha \beta}$ & $\left(\mathrm{Mg}_{72} \mathrm{Zn}_{23} \mathrm{Ca}_{5}\right)$ \\
\hline $\mathrm{Mg}-\mathrm{Mg}$ & 1.19 & 1.20 & 0.00 & -0.01 \\
$\mathrm{Mg}-\mathrm{Zn}$ & 0.62 & 0.66 & 0.06 & 0.10 \\
$\mathrm{Mg}-\mathrm{Ca}$ & 0.95 & 1.00 & -0.41 & -0.36 \\
$\mathrm{Zn}-\mathrm{Mg}$ & 1.11 & 1.20 & -0.12 & -0.02 \\
$\mathrm{Zn}-\mathrm{Zn}$ & 0.71 & 0.66 & 0.27 & 0.22 \\
$\mathrm{Zn}-\mathrm{Ca}$ & 1.21 & 1.00 & -0.47 & -0.76 \\
$\mathrm{Ca}-\mathrm{Mg}$ & 1.13 & 1.20 & -0.06 & 0.04 \\
$\mathrm{Ca}-\mathrm{Zn}$ & 0.81 & 0.66 & 0.07 & -0.10 \\
$\mathrm{Ca}-\mathrm{Ca}$ & 0.67 & 1.00 & 0.25 & -0.09 \\
\hline
\end{tabular}

TABLE III: The observed ratio $\mathrm{CN}_{r}=\mathrm{CN}\left(\mathrm{Mg}_{72} \mathrm{Zn}_{23} \mathrm{Ca}_{5}\right) / \mathrm{CN}\left(\mathrm{Mg}_{60} \mathrm{Zn}_{35} \mathrm{Ca}_{5}\right)$ of partial coordination numbers between the two compositions, and the ratio expected $\mathrm{CN}_{\text {hom }}$ where the atoms are distributed homogeneously. The chemical short-range order parameter $\eta_{\alpha \beta}$ is also given. 


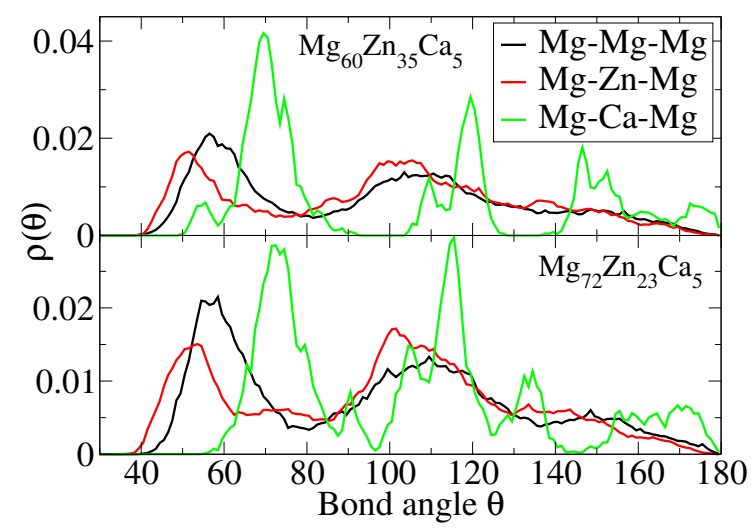

FIG. 4: $\quad \mathrm{Mg}-\{\mathrm{Mg}, \mathrm{Zn}, \mathrm{Ca}\}-\mathrm{Mg}$ bond-angle distributions $\rho(\theta)$ for the $\mathrm{Mg}_{60} \mathrm{Zn}_{35} \mathrm{Ca}_{5}$ (top) and $\mathrm{Mg}_{72} \mathrm{Zn}_{23} \mathrm{Ca}_{5}$ (bottom) compositions.

the number concentration of species $\alpha$ and $\mathrm{CN}_{\alpha}$ is the total coordination number of species $\alpha[10,43]$. If $\eta_{\alpha \beta}=0$, then no preference is observed, with negative values of $\eta_{\alpha \beta}$ implying a preferred association between species $\alpha$ and $\beta$. Contrary to the suggestion of Andonov and Chieux [26], but as observed in later simulations [29] including through calculation of the CSRO [10], we see a moderate avoidance of Zn-Zn bonding over Zn-Mg or Zn-Ca.

The Mg-X-Mg bond-angle distributions are given in Figure 4. They are rather similar for both compositions. The Mg-Mg-Mg bond-angle distribution has a peak centred on $\sim 60$ degrees and a broader peak centred on $\sim 110$ degrees, as well as a much broader peak at angles of $~ 150$ degrees. The first peak of the Mg-Zn-Mg bond-angle distribution occurs at smaller angles ( 50 degrees), and the second peak is close to that of the $\mathrm{Mg}-\mathrm{Mg}-\mathrm{Mg}$ bond-angle distributions. The $\mathrm{Mg}-\mathrm{Ca}-\mathrm{Mg}$ and other bond-angle distributions are difficult to extract meaningful data from, due to the low number of atoms, hence some are not shown. The ideal icosahedral bond angles are $\sim 63.5, \sim 116.5$ and 180 degrees, providing further evidence of the presence of icosahedral and related motifs in the glass structure.

Icosahedral structural motifs are found in both models: $7 \%$ of $\mathrm{Mg}$ atoms and $7 \%$ of $\mathrm{Zn}$ atoms in $\mathrm{Mg}_{60} \mathrm{Zn}_{35} \mathrm{Ca}_{5}$, and $3 \%$ of $\mathrm{Mg}$ atoms in $\mathrm{Mg}_{72} \mathrm{Zn}_{23} \mathrm{Ca}_{5}$ are at the centres of icosahedra. The medium-range structure of metallic glasses is often defined in terms of Voronoi polyhedra. The Voronoi polyhedron for a given atom is the three-dimensional shape which contains all points in space closer to that atom than to any other atom. Voronoi 
polyhedra are characterised by their signature $\left(v_{3}, v_{4}, v_{5}, v_{6}, \ldots\right)$, where $v_{n}$ is the number of faces of the polyhedron containing $n$ edges. An icosahedron has twelve pentagonal faces, hence has a Voronoi signature of $(0,0,12,0)$. This method of characterising the structure is complementary to analysing the coordination numbers discussed earlier; due to the different cutoffs for different interactions, the total coordination number is not necessarily equal to $\sum_{n=3}^{\infty} v_{n}$.

We computed the Voronoi polyhedra and their signatures for the last timestep for each of the configurations. Although $(0,0,12,0)$ icosahedra exist, they do not dominate: $11 \%$ of $\mathrm{Mg}$ atoms in $\mathrm{Mg}_{60} \mathrm{Zn}_{35} \mathrm{Ca}_{5}$ and $6 \%$ of $\mathrm{Mg}$ atoms in $\mathrm{Mg}_{72} \mathrm{Zn}_{23} \mathrm{Ca}_{5}$ have a related $(0,2,8,2)$ signature. For $\mathrm{Zn}$ atoms, $10 \%$ in $\mathrm{Mg}_{60} \mathrm{Zn}_{35} \mathrm{Ca}_{5}$ and $7 \%$ in $\mathrm{Mg}_{72} \mathrm{Zn}_{23} \mathrm{Ca}_{5}$ have a $(0,1,10,2)$ signature, and $5 \%$ in $\mathrm{Mg}_{60} \mathrm{Zn}_{35} \mathrm{Ca}_{5}$ and $7 \%$ in $\mathrm{Mg}_{72} \mathrm{Zn}_{23} \mathrm{Ca}_{5}$ have a $(0,0,12,2)$ signature. $\mathrm{Zn}$ has a lower, and $\mathrm{Ca}$ a higher, average coordination number than $\mathrm{Mg}$, decreasing the likelihood of icosahedra forming around them. A similar very wide range of Voronoi polyhedra was found in other simulations [10, 29].

\section{CONCLUSION}

We have performed first-principles molecular dynamics simulations of two biomedically relevant compositions of $\mathrm{Mg}-\mathrm{Zn}-\mathrm{Ca}$ glass. Bond lengths found were in agreement with experimental and simulated results from other compositions, and the local atomic environments were not found to change with composition. The local environments were quite different for the different species, with average coordination numbers of 13 for $\mathrm{Mg}, 11$ for $\mathrm{Zn}$, and $18-19$ for Ca. Through the computation of a chemical short-range order parameter, we observed a moderate avoidance of Zn-Zn bonding, opposing a suggestion from experimental work [26], but as also observed in simulation [10, 29]. These two compositions were chosen for simulation because of their different behaviour when implanted into the body, with the high- $\mathrm{Zn}$ composition forming a passivating Zn-rich surface layer, which the low-Zn composition does not exhibit [11]; the reason for this is not clear from our studies of the bulk structure.

Icosahedral structural motifs are known to be prevalent in related glass compositions [1922 ] and in metallic glasses more generally [23-25], where their presence is linked to increased glass-forming ability. For these compositions, they occurred in rather low numbers, typically

less than $10 \%$, although due to the very wide range of local atomic structures, icosahedra 
and related environments were among the most common observed. Again, no significant change was observed for the two different compositions.

It is clear that to characterise fully the medium-range structural environment, as well as elucidate any composition-dependent changes, we will need to study larger models of these glasses. This will require the use of empirical potentials such as those previously developed for related systems [19-21, 28]; these potentials require careful validation before use and the data obtained in this paper will be invaluable to achieve this, through, e.g. comparison of the interatomic forces simulated classically and ab initio.

This work was funded by a UCL Excellence Fellowship and the UK's EPSRC (EP/L024195). Computer time was awarded by the UK's HPC Materials Chemistry Consortium, funded by EPSRC (EP/L000202), and by UCL Research Computing.

[1] A. L. Greer, Science 267, 1947 (1995).

[2] C. A. Schuh, T. C. Hufnagel, and U. Ramamurty, Acta Mater. 55, 4067 (2007).

[3] A. Inoue, Acta Mater. 48, 279 (2000).

[4] D. Wang, Y. Li, B. B. Sun, M. L. Sui, K. Lu, and E. Ma, Appl. Phys. Lett. 84, 4029 (2004).

[5] A. Peker and W. L. Johnson, Appl. Phys. Lett. 63, 2342 (1993).

[6] A. L. Greer, Materials Today 12, 14 (2009).

[7] Y. Q. Cheng and E. Ma, Prog. Mat. Sci. 56, 379 (2011).

[8] X. Gu, Y. Zheng, S. Zhong, T. Xi, J. Wang, and W. Wang, Biomaterials 31, 1093 (2010).

[9] Y. B. Wang, X. H. Xie, H. F. Li, X. L. Wang, M. Z. Zhao, E. W. Zhang, Y. J. Bai, Y. F. Zheng, and L. Qin, Acta Biomater. 7, 3196 (2011).

[10] R. Mahjoub, K. J. Laws, J. P. Scicluna, J. E. Daniels, and M. Ferry, Comp. Mat. Sci. 96, 246 (2015).

[11] B. Zberg, P. J. Uggowitzer, and J. F. Löffler, Nature Mater. 8, 855 (2009).

[12] E. Ma and J. Xu, Nature Mater. 8, 855 (2009).

[13] J. D. Cao, N. T. Kirkland, K. J. Laws, N. Birbilis, and M. Ferry, Acta Biomater. 8, 2375 (2012).

[14] A. Tilocca, Proc. R. Soc. A 465, 1003 (2009).

[15] J. K. Christie and A. Tilocca, Chem. Mater. 22, 3725 (2010). 
[16] J. K. Christie and A. Tilocca, J. Mater. Chem. 22, 12023 (2012).

[17] J. K. Christie and A. Tilocca, J. Phys. Chem. B 116, 12614 (2012).

[18] J. K. Christie, R. I. Ainsworth, D. Di Tommaso, and N. H. de Leeuw, J. Phys. Chem. B 117, 10652 (2013).

[19] Z.-Y. Hou, R.-S. Liu, Z.-A. Tian, and J.-G. Wang, Chin. Phys. B 20, 066102 (2011).

[20] Y.-C. Liang, R.-S. Liu, Y.-F. Mo, H.-R. Liu, Z.-A. Tian, Q.-Y. Zhou, H.-T. Zhang, L.-L. Zhou, Z.-Y. Hou, and P. Peng, J. Alloys and Comp. 597, 269 (2014).

[21] Z.-Y. Hou, R.-S. Liu, C.-L. Xu, X.-M. Shuai, and Y. Shu, Trans. Nonferrous Met. Soc. China 24, 1086 (2014).

[22] M. Durandurdu, J. Chem. Phys. 137, 034503 (2012).

[23] Y. Q. Cheng, E. Ma, and H. W. Sheng, Phys. Rev. Lett. 102, 245501 (2009).

[24] U. Kühn, J. Eckert, N. Mattern, and L. Schultz, Appl. Phys. Lett. 80, 2478 (2002).

[25] X. D. Wang, S. Yin, Q. P. Cao, J. Z. Jiang, H. Franz, and Z. H. Jin, Appl. Phys. Lett. 92, $011902(2008)$.

[26] P. Andonov and P. Chieux, J. Non-Cryst. Sols. 93, 331 (1987).

[27] O. N. Senkov, D. B. Miracle, E. R. Barney, A. C. Hannon, Y. Q. Cheng, and E. Ma, Phys. Rev. B 82, 104206 (2010).

[28] S.-P. Ju, H.-H. Huang, and J. C.-C. Huang, J. Non-Cryst. Sols. 288, 23 (2014).

[29] S. N. Li, J. B. Liu, J. H. Li, J. Wang, and B. X. Liu, J. Phys. Chem. B 119, 3608 (2015).

[30] J. Vandevondele, M. Krack, F. Mohamed, M. Parrinello, T. Chassaing, and J. Hutter, Comp. Phys. Comm. 167, 103 (2005).

[31] J. P. Perdew, K. Burke, and M. Ernzerhof, Phys. Rev. Lett. 77, 3865 (1996).

[32] J. VandeVondele and J. Hutter, J. Chem. Phys. 127, 114105 (2007).

[33] S. González, E. Pellicer, J. Fornell, A. Blanquer, L. Barrios, E. Ibáñez, P. Solsona, S. Suriñach, M. D. Baró, C. Nogués, et al., J. Mech. Behav. Biomed. Mater. 6, 53 (2012).

[34] J. K. Christie and A. Tilocca, Adv. Engin. Mat. 12, B326 (2010).

[35] J. K. Christie, A. Pedone, M. C. Menziani, and A. Tilocca, J. Phys. Chem. B 115, 2038 (2011).

[36] E. Tang, D. Di Tommaso, and N. H. de Leeuw, Adv. Engin. Mater. 12, B331 (2010).

[37] J. K. Christie, R. I. Ainsworth, and N. H. de Leeuw, Biomaterials 35, 6164 (2014).

[38] R. I. Ainsworth, J. K. Christie, and N. H. de Leeuw, Phys. Chem. Chem. Phys. p. in press 
(2014).

[39] E. Tetik, M. Durandurdu, and F. Karadag, EPL 100, 26002 (2012).

[40] M. Durandurdu, Solid State Comm. 154, 30 (2013).

[41] M. Durandurdu, J. Chem. Phys. 137, 034503 (2012).

[42] O. N. Senkov, Y. Q. Cheng, D. B. Miracle, E. R. Barney, A. C. Hannon, and C. F. Woodward, J. Appl. Phys. 111, 123515 (2012).

[43] J. M. Cowley, J. Appl. Phys. 21, 24 (1950). 